\title{
AN EXPERIMENTAL ANALYSIS AND WELDING PARAMETER OPTIMIZATION IN FRICTION STIR WELDING FOR ALUMINUM
}

\section{AND MAGNESIUM ALLOY MATERIALS}

\section{AMIT H. KARWANDE ${ }^{1} \&$ SEERAM SRINIVASA RAO ${ }^{2}$}

${ }^{I}$ Research Scholar, Department of Mechanical Engineering, Koneru Lakshmaiah Education Foundation,

\author{
Vaddeswaram, Andhra Pradesh, India
}

${ }^{2}$ Professor, Department of Mechanical Engineering, Koneru Lakshmaiah Education Foundation,

Vaddeswaram, Andhra Pradesh, India

\begin{abstract}
Friction stir welding (FSW) is a welding phenomenon where metals are plasticized and joint with suitable applied pressure. It is a solid state of welding process with non-consumable tool. Magnesium alloy materials like AZ31 and AZ91 are selected in this experimental work. Because, this alloys having low density as compare to steel so it is lighter in weights. Also this material are having good strength, ductility and corrosion resistance [21]. A taguchi approach along with design of experiment (DOE) methodology are used to optimize weld parameter. Rotating seed, transverse speed and materials are selected as a working parameter for experimentation. After a weld tensile test is used to determine different design parameter of different weld specimen.

KEYWORDS: AZ31- AZ91, DOE \& FSW
\end{abstract}

Received: Mar 21, 2019; Accepted: Apr 11, 2019; Published: May 10, 2019; Paper Id.: IJMPERDJUN201981

\section{INTRODUCTION}

FSW is a comparatively new welding process that was developed and patented by the welding institute in 1991, initially for aluminum and its alloys. It is a solid-state hot-shear joining process in which a rotating tool with a shoulder and a pin moves along the weld seam [3] as shown in figure 1.

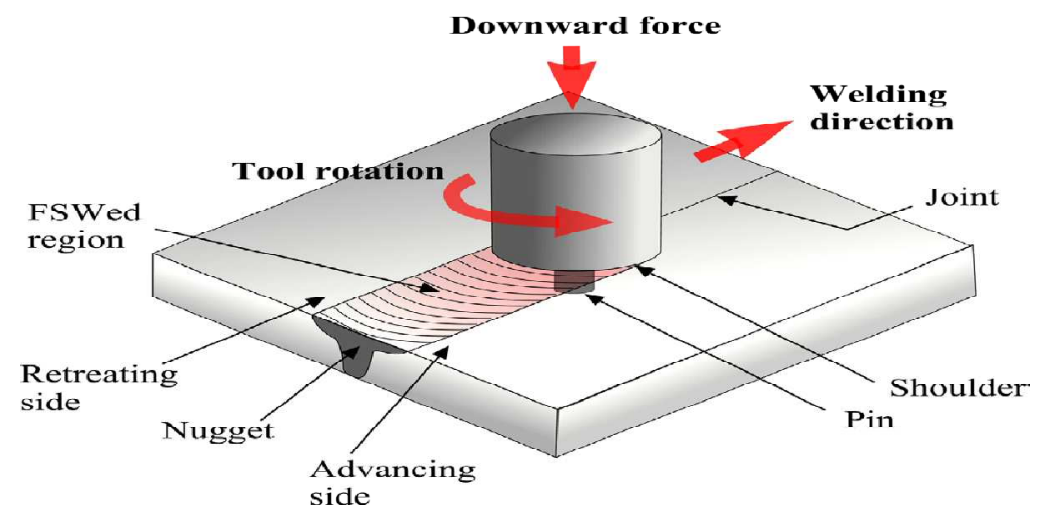

Figure 1: Schematic Representation of the FSW Process [2]

It is a metal joining technique named friction stir welding developed to weld aluminum, magnesium and other lightweight materials [4]. Friction stir welding ability of 5\% SiC particulate aluminum matrix cast composite 
using TiAlN coated tool and effect of process parameters such as tool rotation speed, traverse speed, and axial force on ultimate tensile strength were investigated.[C. Devanathan et.al, 2014]. Also, the mechanical behavior and weld microstructure were studied over a wide range of tool rotational speeds and tool-pin temperatures.[Bhandari Vijendra et.al, 2015]. The main objectives of the present investigation were rather than microstructure study an optimization technique is used to observe weld behavior. With variation of welding parameter in sequence a different weld strength is observed. As it will take more experimental time and cost too. So, it is necessary to gone through DOE. Magnesium alloy material as AZ31 and AZ91 are gone through FSW. The dimensions of work piece is $150 \mathrm{~mm} \times 50 \mathrm{~mm}$ with $5 \mathrm{~mm}$ of thick sheet. All the testing of welded part tested after ASTM standard then go for experimentation on Universal Testing Machine.

\section{COMPOSITION OF MATERIAL AND TOOL}

In this work alloy material of magnesium also being used as AZ31 and AZ91. This two material is selected for comparative result study over aluminum alloy. Because this alloys having low density as compare to aluminum. The composition of alloys of magnesium the $\mathrm{AZ} 31$ is $2.75 \% \mathrm{Al}, 0.001 \% \mathrm{Fe}, 0.91 \% \mathrm{Zn}, 0.01 \% \mathrm{Mn}$ and magnesium for balance and AZ91 having the composition as $8.67 \% \mathrm{Al}, 0.002 \% \mathrm{Fe}, 0.85 \% \mathrm{Zn}, 0.03 \% \mathrm{Mn}$ and magnesium for balance and mechanical properties of alloys as AZ31 having tensile strength of $272 \mathrm{~N} / \mathrm{mm} 2$ and elongation is $7.2 \%$, and AZ91 having tensile strength of $240 \mathrm{~N} / \mathrm{mm} 2$ and elongation is $16.8 \%$.[21] The material is brought from Venuka Engineering solutions, Kaylan, Mumbai. The dimension work piece to be weld is shown in figure 3 and figure 4 shows its actual view.

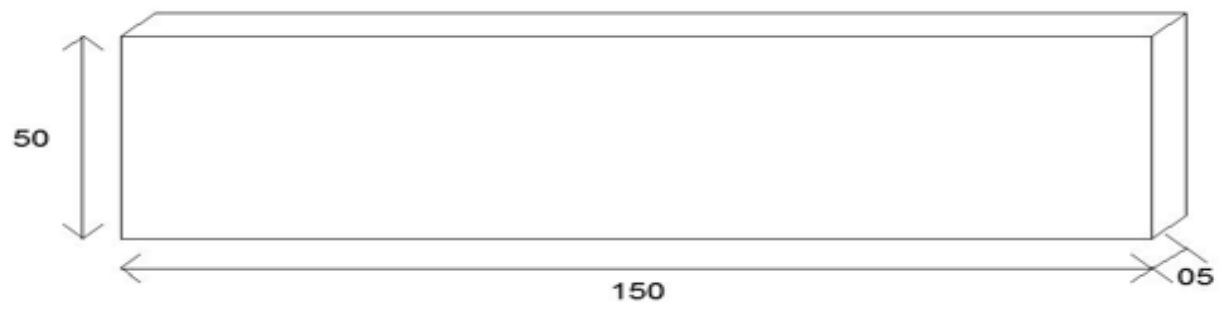

Figure 2: Dimensions of Base Materials for Magnesium Alloy Materials (All Dimension in mm)

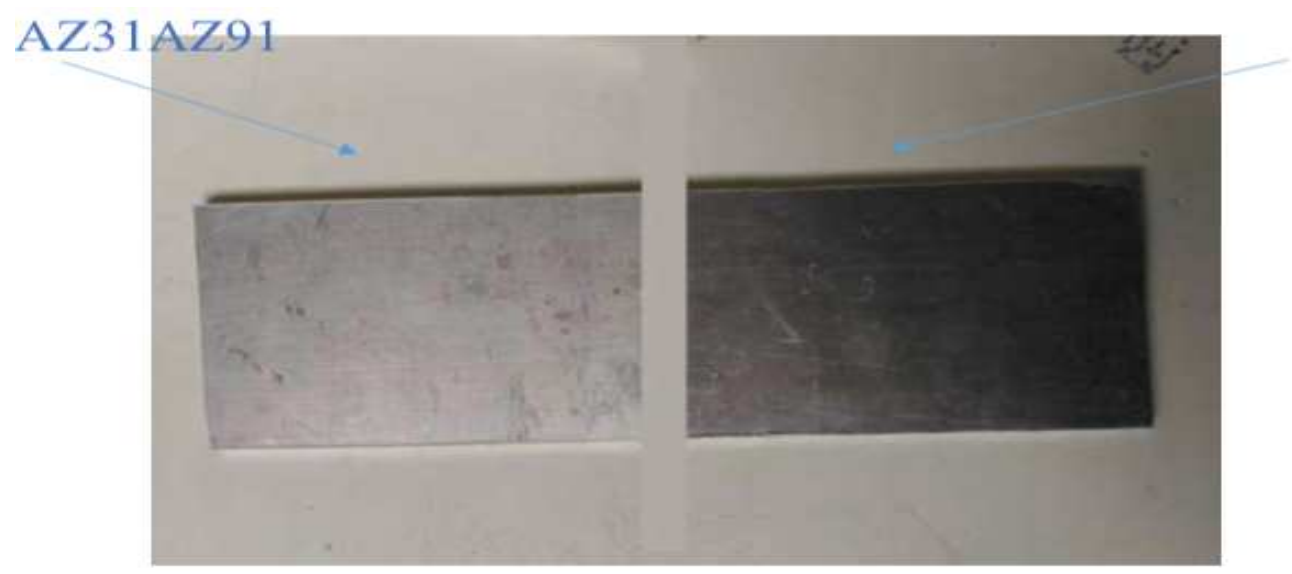

Figure 3: Actual View of Base for Magnesium Alloy Materials as AZ31 and AZ91

Weld quality along with tool wear are vitalparameter to tool material for welding process. The microstructure of welding materials are also important parameter in FSW. For a better FSW weld tool should soften the material flow with a proper hold within holder. The material of the tool H13 steel was used[21]. The Dimensions of the tool is shown below with all dimension in mm along actual tool used in welding process. 


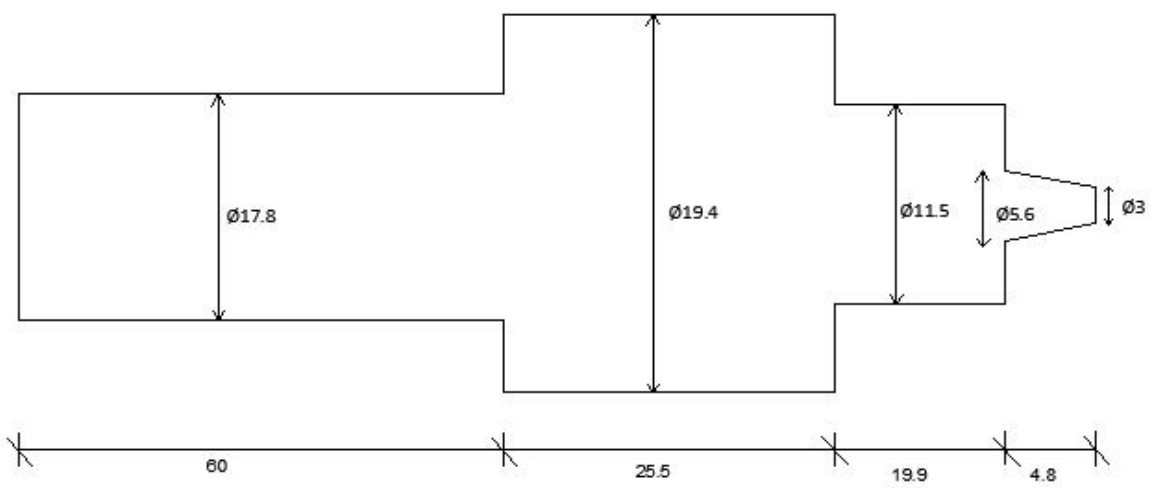

Figure 4: Geometry of Tool (All Dimension in mm)

These are some tool mostly used in FSW are-

1. Skew-Stir Tool 2. Com-Stir tools 3. Dual-Rotation Tool 4. Re-Stir Tool[21].

\section{TAGUCHI APPROACH AND DOE}

Optimization is the vital tool which being used now a day in engineering application and welding is no exception for it. Taguchi not only enhance quality but also observe process parameter variation. In this work taguchi along with DOE is used for experimentation. Parameters are selected as per the DOE which provides a best tool to achieve not only the quality of product but also process efficiency [21]. When a large number of experimental works have to be carried out when the number of process parameters increases. Therefore to reduce the number of experiments and to obtain good quality of investigation the term named DOE. It is factorial design and linear regression techniques have been widely used in engineering analysis. These techniques consist of experiments with an objective of acquiring data in a controlled way, executing these experiments in order to obtain information about the behavior of a given process [22]. DOE is used for calculating the independent variable values at as per limited different experiments. Orthogonal array in the experiments will help the designers to understand the influence of multiple controllable factors with the quality average characteristics and the variations of physical parameter in a fast and economic way. Number of experiments performed as per selection of process parameters. In order to obtain this task, the Taguchi method with orthogonal arrays is vital tool [21]. The design of experiments is the shortest method for experimentation evaluation which gives the variation of physical parameter who affecting more to experimentation.

Following table gives working parameter with their experimentation level.

Table 1: Working Parameters and their Levels[21]

\begin{tabular}{|c|c|c|c|}
\hline Parameters/Level & Rotating Speed(rpm) & $\begin{array}{c}\text { Transverse Speed } \\
(\mathbf{m m} / \mathbf{m i n} .)\end{array}$ & Material \\
\hline 1 & 1000 & 60 & AZ31 \\
\hline 2 & 1200 & 75 & AZ91 \\
\hline 3 & 1400 & 80 & AZ31 \& AZ91 \\
\hline
\end{tabular}

\section{EXPERMENTATION}

In order to reduce number of experiment frequency; an orthogonal array is used. In this work $\mathrm{L}_{9}$ orthogonal array is used to start experimental work. 
Table 2: Working Parameter Section Using L, Orthogonal Array

\begin{tabular}{|c|c|c|l|}
\hline Sr. No. & Parameter 1 & Parameter 2 & Parameter 3 \\
\hline 1. & 1000 & 60 & AZ91 \\
\hline 2. & 1000 & 75 & AZ31 \\
\hline 3. & 1000 & 80 & AZ31 \& AZ91 \\
\hline 4. & 1200 & 60 & AZ31 \\
\hline 5. & 1200 & 75 & AZ31 \& AZ91 \\
\hline 6. & 1200 & 80 & AZ91 \\
\hline 7. & 1400 & 60 & AZ31 \& AZ91 \\
\hline 8. & 1400 & 75 & AZ91 \\
\hline 9. & 1400 & 80 & AZ31 \\
\hline
\end{tabular}

In this work cylinder type of welding tool is used for the welding purpose. Prior welding process fixture is design as per convenience of weld. A vertical milling machine is for the welding process which can apply significant pressure on the work piece. Welding ids done at small scale workshop at kopergao, Maharashtra (India). Experiments were conducted as per the design levels of DOE (i.e. as per $\mathrm{L}_{9}$ orthogonal array as shown in Table 2).



(a)

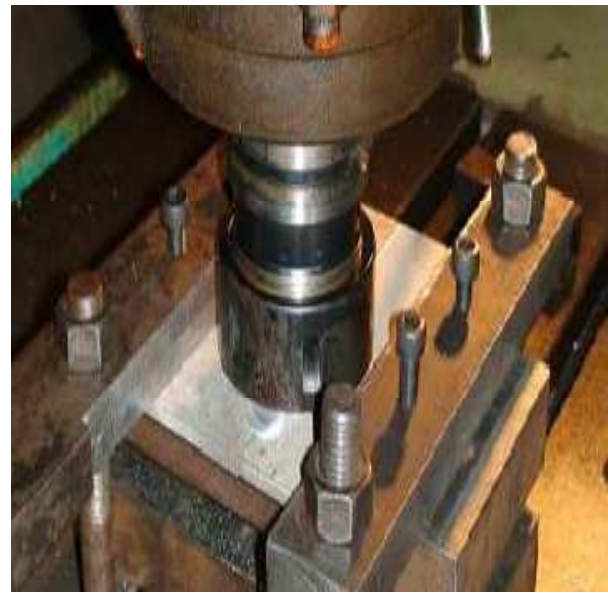

(b)

Figure 5: (a) and (b) FSW Welding Using Vertical Milling Machine

\section{RESULTS AND DISCUSSIONS}

After welding of different specimen it goes under tensile test followed by microstructure analysis. Figure 1 and 8 show the test specimen after welding as pea ASME standards.

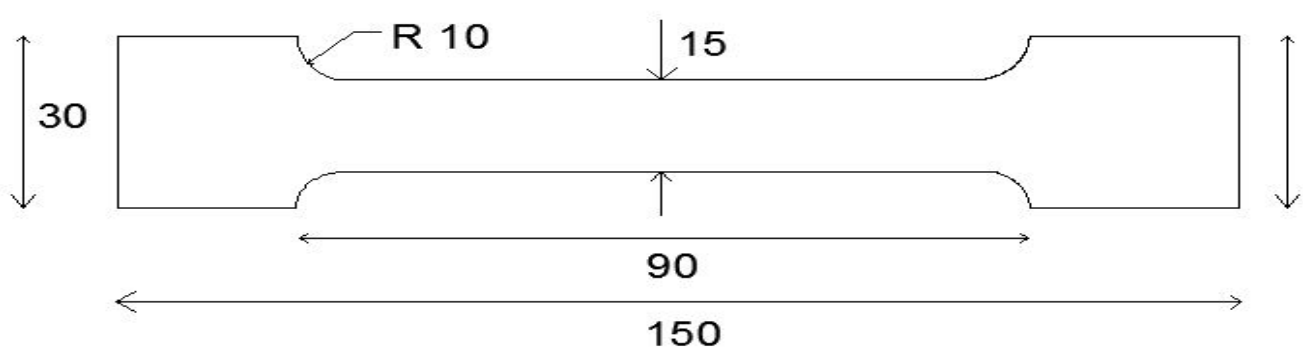

Figure 6: Weld Specimen as per ASTM Standards (All Dimension in mm) 


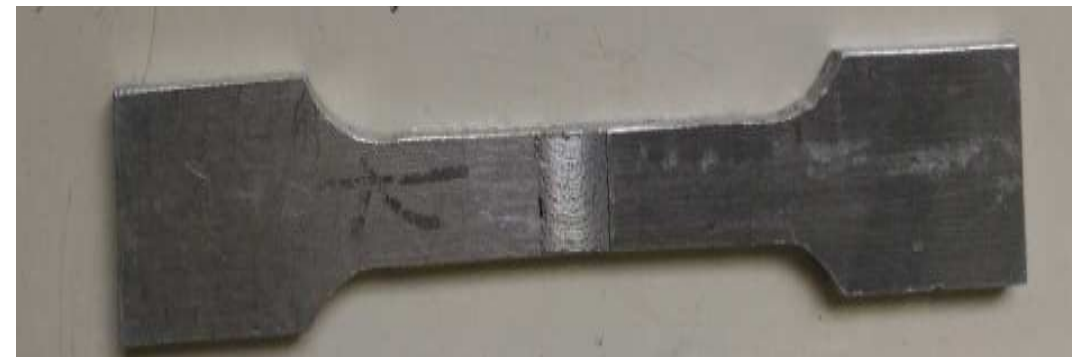

Figure 7: Actual View of Specimen after Weld

UTM testing is done in SND College of Engineering \& Research Centre, yeola for above mentioned specimen.

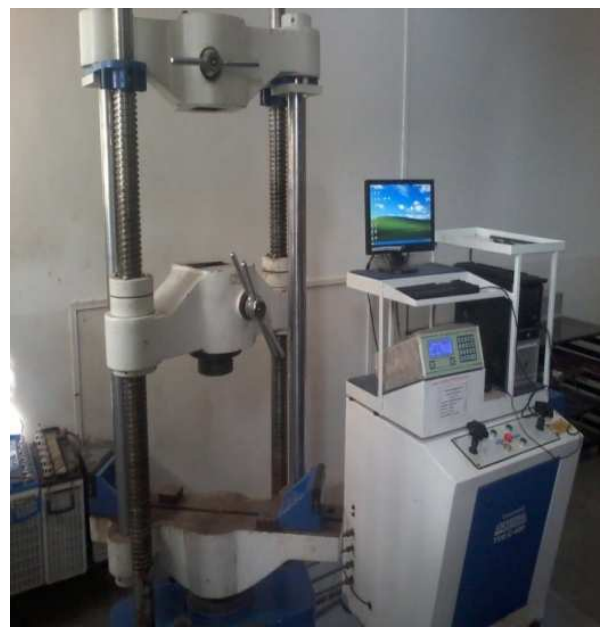

(a)

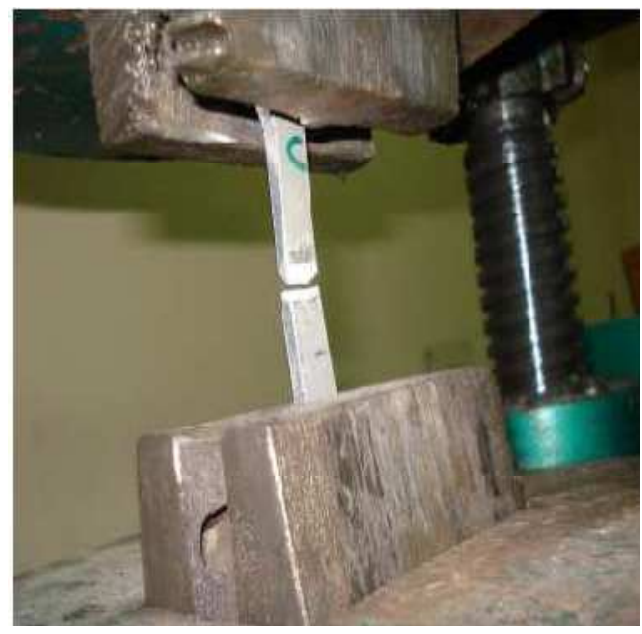

(b)

Figure 8: (a) Tensile Test on the UTM (b) Specimen in UTM (UTM Testing Performed at SND College of Engg. and Research Centre, Yeola)

Specimens for tensile test are as per the standard of ASME (American Society for Testing of Materials). Test was carried out in Universal Testing Machine at a room temperature in SNDCOE\&RC, Yeola as shown in Figure 9.

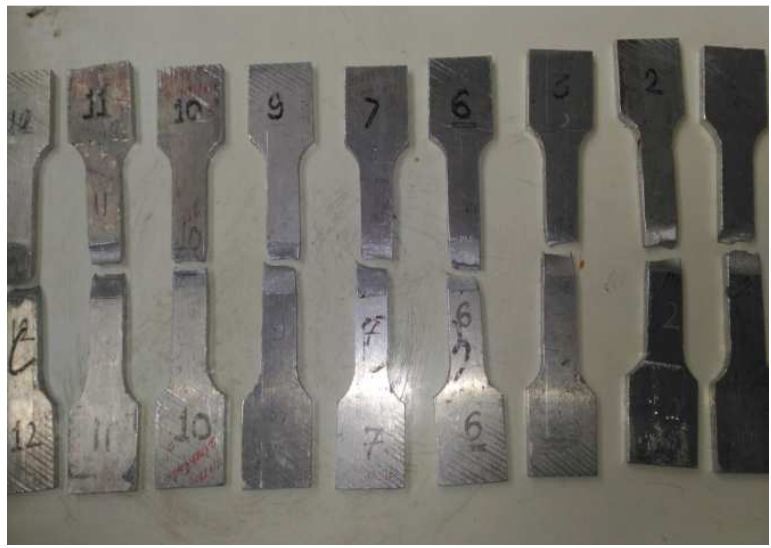

Figure 9: Specimen After Testing on Universal Testing Machine

The welding of magnesium alloy is possible by using FSW process. Mechanical properties like base material joint were found as per the experimentation. The maximum strength of joint is found at 1400rpm rotational speed and 75 $\mathrm{mm} / \mathrm{min}$ transverse speed of AZ91 materials which is shown in Table 3. 
Table 3: Working Parameter Section Using L ${ }_{9}$ Orthogonal Array

\begin{tabular}{|c|c|c|l|l|c|c|}
\hline Sr. No. & Parameter 1 & Parameter 2 & Parameter 3 & UTS & YS & \% ELO \\
\hline 1. & 1000 & 60 & AZ91 & 204.3 & 178.2 & 11.2 \\
\hline 2. & 1000 & 75 & AZ31 & 192.7 & 172.6 & 4.3 \\
\hline 3. & 1000 & 80 & AZ31 \& AZ91 & 180.3 & 169.7 & 4.1 \\
\hline 4. & 1200 & 60 & AZ31 & 196.5 & 174.7 & 6.3 \\
\hline 5. & 1200 & 75 & AZ31 \& AZ91 & 188.6 & 162.5 & 6.7 \\
\hline 6. & 1200 & 80 & AZ91 & 211.4 & 182.6 & 12.9 \\
\hline 7. & 1400 & 60 & AZ31 \& AZ91 & 191.2 & 167.1 & 7.1 \\
\hline 8. & 1400 & 75 & AZ91 & 218.1 & 186.2 & 13.3 \\
\hline 9. & 1400 & 80 & AZ31 & 198.6 & 175.5 & 5.1 \\
\hline
\end{tabular}

The material is important parameter in the FSW process that effect on all parameters of welding, the maximum Ultimate Tensile Strength, Yield Strength and \% of Elongation is found in the joint of plates AZ31 and AZ91 alloy material and minimum UTS and YS is found at the joint of dissimilar plates i.e. in joint of AZ31 and AZ91 alloy material joint. The behavior of UTS, YS and \% EL with respect to different experimental level is shown in graphical form as below.

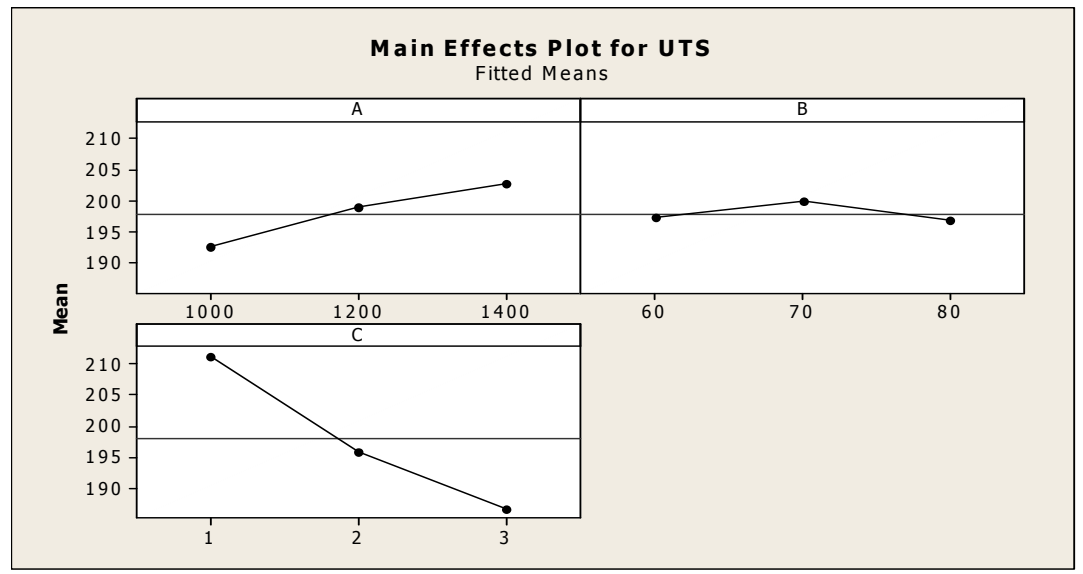

Figure 10:Main Effects Plot for Ultimate Tesnsile Streangth

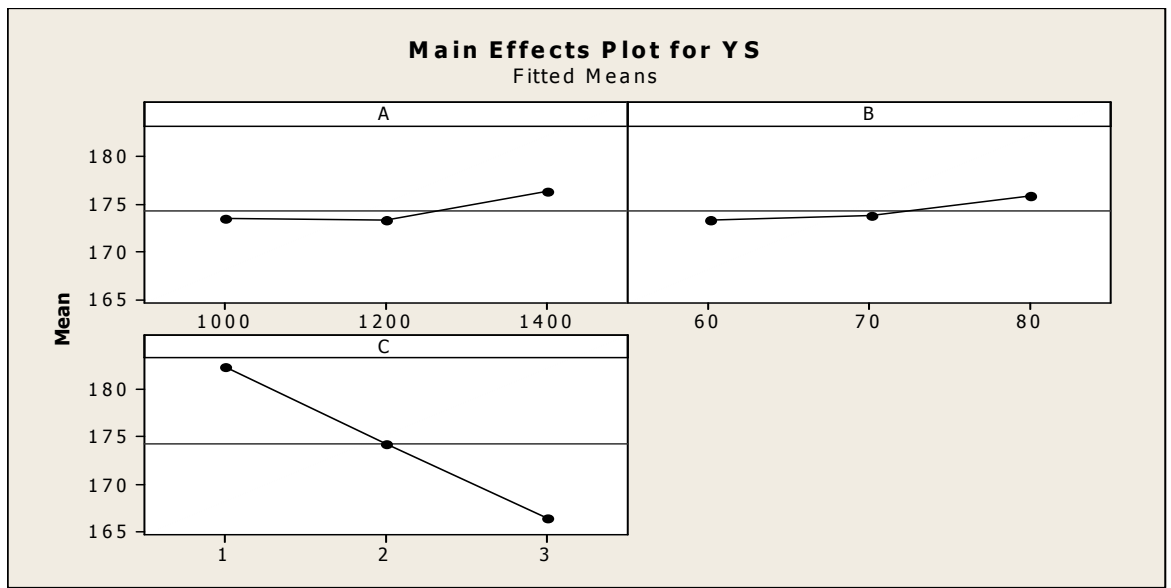

Figure 11: Main Effects Plot for Yield Stress 


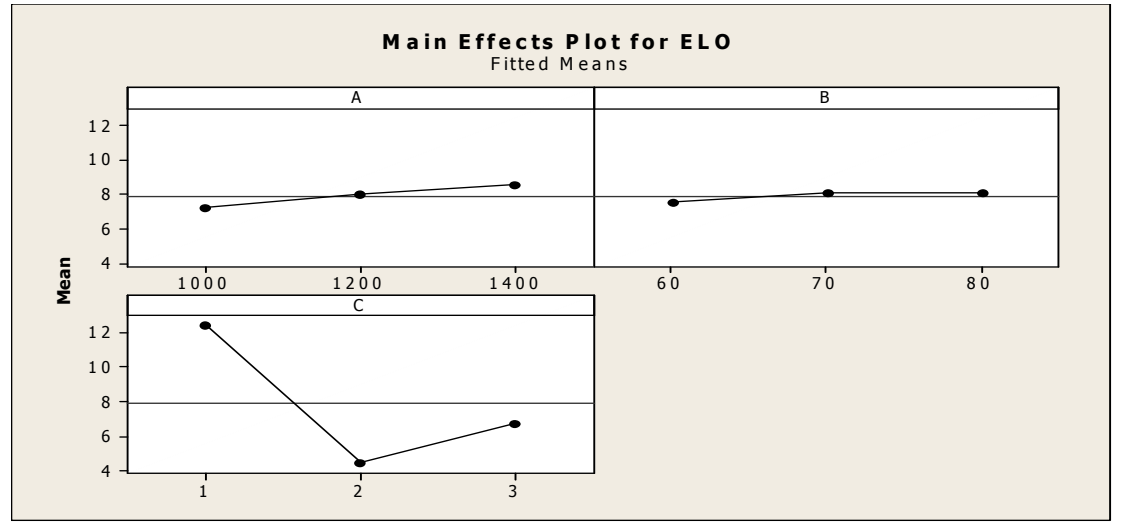

Figure 12: Main Effects Plot for \% of Elongation

Mechanical properties of welded structure like bending strength, fatigue behavior, compressive strength can also be studied. FSW process can be studied for suitability for welding other materials like copper, magnesium, titanium, steel etc. This result will conclude that the welding of magnesium alloy is possible by using friction stir welding process and FSW is best welding process for similar material. The maximum strength of joint is found at 1400rpm rotational speed and $70 \mathrm{~mm} / \mathrm{min}$ transverse speed of AZ31 alloy. The material is important parameter in the friction stir welding process that effect on all parameters of welding, the maximum UTS, YS, \% Elongation is found in the joint of similar plates AZ31 alloy material and minimum UTS and YS is found at the joint of dissimilar plates i.e. In joint of AZ31 and AZ91 alloy material joint. The different mechanical properties of base material joint were found as per the experimentation. The results obtained for different mechanical with DOE shows that the material is more influencing factor in the FSW as the material changes the strength of joint and other parameter also get varies for the welding of that particular material.

\section{REFERENCES}

1. N.T. Kumbhar and G.K. Dev., "Friction stir welding of aluminum alloy”, Barc newsletter, issue no. 321, July-August 2011

2. Mario Guillo and Laurent Dubourg, "Impact \& improvement of tool deviation in friction stir welding: Weld quality \& real-time compensation on an industrial robot”, An international journal of manufacturing, product and process development, Octomber2015

3. BandariVijendra and AbhaySherma, "Induction heated tool assisted friction-stir welding (i- FSW:A novel hybrid process for joining of thermoplastics”, Journals of manufacturing processes, July 2015.

4. C. Devanathan and A.SureshBabu, "Friction Stir Welding of Metal Matrix Composite using Coated tool", 3rd International Conference on Materials Processing and Characterizations (ICMPC 2014), 2014

5. LuriBoromei, LorellaCeschini, Alessandro Morri and Gian Luca Garagnani, "Friction stir welding of aluminium based composites reinforcedwith $\mathrm{Al}_{2} \mathrm{O}_{3}$ particles: Effect on microstructure and charpy impact energy",

6. Joon Tae Yoo, Jong Hoon Yoon, Kyung Ju Min and Ho sung Lee, "Effect of friction stir welding processparameter on mechanical properties and Micro structure of Al-Li alloy”, 2nd int. materials, industrial andmanufacturing egg. Conference, 2015.

7. Dong woo kim, Myeong-Woo Cho, Tae-Il Seo and Eung-Sug Lee, "Application of Design of ExperimentMethod for Thrust Force Minimization in Step-feed Micro Drilling”, published in january 2008.

8. Uguresme(2009), “Application of taguchi methods for optimization of resistance spot welding process," mersin university, tarsus technical education, the Arabian journal for science and engineering, vol. 34, 2009. 
9. N A Husain, H Khodaparast, A Snaylam, S James, G Dearden, and H Ouyang, department of engineering, university of liverpool, Liverpool, U.K. the manuscript was received on 16 June 2009 and was accepted after revision for publication on 2 october 2009.

10. M. Mehta, G.M. Reddy and A.V. Rao, "Numerical modeling of friction stir welding using the tools withpolygonal pins", defense technology, 2015.

11. UgenderSingarapu, Kumar Adepu and Somi Reddy Arumalle, "Influence of tool material and rotationalspeed on mechanical properties of friction stir welded AZ31B magnesium alloy”, journal of magnesium andalloy, 2015.

12. R. Rai, A. De, H.K.D.H. Bhadeshia and T. Deb Roy, "Review: Friction Stir Welding Tools, Science andTechnology of Welding and joining”, Vol. 16 No.4”, 2011.

13. Yunus, Mohammed., \& Alsoufi, M. S. (2015). A statistical analysis of joint strength of dissimilar aluminium alloys formed by friction stir welding using taguchi design approach, anova for the optimization of process parameters. IMPACT: International Journal of Research in Engineering \& Technology (IMPACT: IJRET), 3(7), 63-70.

14. S.M. Bayazid, H.Farhangi and A. Ghahramani, "Investigation of friction stir welding parameters of 6063-7075 Aluminum alloys by Taguchi method", 5th int. conference on in 2015.

15. Xiaocong He, FengshouGu, Andrew Ball, "A review of numerical analysis of friction stir welding, Progressin material science”, 2014.

16. SK Seshacharyulu, K., Bandhavi, C., Naik, B.B., Rao, S.S., Singh, "Understanding Friction in sheet metal forming-A review”,Materials Today 5 (9), 18238-18244.

17. Qiu-zheng Zhang, wen-biao and Wei Liu, (2015), "Microstructure and mechanical properties of dissimilarAl-Cu joints by Friction stir welding," pp.1779-1786.

18. Prasad Rao Kalvala, JavedAkram, Mano Mishra, Damodaram Ramachandran and Janki Ram Gabbita," Lowtemperature friction stir welding of P91 steel, defense technology”, 2015

19. Sungookyoon, Rintarouegi and HindetoshiFujii, "Effect of initial microstructure on Ti-6Al-4V joint byfriction stir welding, material and design”, 2015.

20. Jae Hyung Cho, Won jae Kim and Chang Gil Lee, "Evaluation of microstructure and mechanical propertiesduring friction stir welding of A5083 and A6082”, 11TH INT. CONFERENCE ON TECHNOLOGY OFPLASTICITY, 2014.

21. Rathod, C. H. A. N. D. A. R., \& Reddy, G. K. (2016). Experimental investigation of angular distortion and transverse shrinkage in CO2 arc welding process. International Journal of Mechanical Engineering, 5(4), 21-28.

22. R.S. Mishra and Z.Y. Ma, "Friction stir welding and processing, Center for Friction Stir processing", department of materials science and engineering, university of missouri, rolla, 2005.

23. Amit H. Karwande, SeeramSrinivasa Rao. "Welding parameter optimization of alloy material by friction stir welding using Taguchi approach and design of experiments", AIP Publishing, 2018.

24. S.G. Amaren, D.S. Yawas, S.Y. Aku. "Effect of periwinkles shell particle size on the wear behavior of asbestos free brake pad", Results in Physics, 2013 